\section{Is it time to retire fragile $X$ testing as a first-tier test for developmental delay, intellectual disability, and autism spectrum disorder?}

To the Editor: We read with great interest the article by Weinstein et al., "Do the Data Really Support Ordering Fragile X Testing as a First-Tier Test Without Clinical Features?," describing the diagnostic yield of chromosomal microarray (CMA) and fragile X (FX) testing for males with intellectual disability (ID) and/or autism spectrum disorder (ASD) in one health-care system. As stated by the authors, developmental delay (DD), ID, and ASD are a group of highly prevalent neurodevelopmental disorders with strong genetic contributions that account for a large proportion of genomic testing requests. Fragile $\mathrm{X}$ syndrome has been reported as the most common source of inherited ID and is caused by a repeat expansion in the X-linked FMR1 gene. Testing for FX is gene-targeted to establish a diagnosis. ${ }^{2}$ Currently, according to the American College of Medical Genetics and Genomics and the American Academy of Pediatrics, the first-tier genetic tests for individuals with $\mathrm{DD}$, ID, and/or ASD include CMA and then FX in males. ${ }^{2-6}$ However, with the rapid advancement of clinical genomic testing and the plethora of diagnostic yield studies in the literature, these practice guidelines may need to be revisited. In the study by Weinstein et al. ${ }^{1}$ the diagnostic yield for FX testing in males with ID and ASD was 2.5\% (2/80) and $0 \%(0 / 75)$, respectively. The limited yield of testing in their cohort supports an ongoing conversation among medical geneticists: should FX testing be considered as a first-tier diagnostic test for individuals with DD, ID, and/or ASD in the absence of syndrome-specific physical findings or a family history suggestive of fragile $\mathrm{X}$ etiology?

Our clinical experience at the UCLA Medical Center over the past 15 years has suggested that the yield of FX testing is limited in populations with DD, ID, and ASD. ${ }^{7}$ We therefore sought to examine the above observation made by Weinstein et al. ${ }^{1}$ through expansion of the total number of cases examined. We performed our own retrospective analysis of males with DD, ID, and/or ASD who underwent diagnostic FX testing from January 2002 to March 2017 at the UCLA Molecular Diagnostics Laboratories. The cohort was identified through a pathology-based electronic medical record system. We excluded all males who were being tested for ataxia with no ID, DD, or ASD. Overall, we identified 654 males ranging in age from 1 to 21 years with DD, ID, and/or ASD who had
FX testing. The yield of FX testing for these patients was 0/654 $(0 \%)$. Our diagnostic yield is comparatively similar to other studies $^{1,8,9}$ and is supported by the largest cohort examined to date. The zero diagnostic yield for FX testing in our DD, ID, and/or ASD cohort could be due to cases of FX being excluded from our cohort by early diagnosis from classical symptoms or family history, which supports the concept that FX testing may be warranted particularly in those instances.

Given the rapidly evolving genomic diagnostic testing landscape, it appears imperative that practice guidelines adapt swiftly and accordingly. For example, prior to 2010, guidelines for clinical genetic testing recommended G-banded karyotype as the gold standard test for the detection of chromosomal imbalance in patients with ID, DD, and ASD in addition to FX testing. This was in spite of the frequent use and widespread adoption of chromosomal microarray analysis in clinical practice. It was not until 2010, after a series of largedata-set articles were published on the diagnostic yield of ID, $\mathrm{DD}$, and/or ASD by CMA (determined to be $7-20 \%{ }^{6,8}$ ), that the guidelines were updated to implement CMA as a first-tier diagnostic test. ${ }^{8}$ The review of data from our cohort supports the need to revisit the guidelines of genetic evaluation for patients with $\mathrm{DD}, \mathrm{ID}$, and ASD, particularly in the era of genome-wide testing.

In conclusion, FX testing should be retired as a first-tier test but remain as part of the differential, particularly when well-defined features (physical and behavioral characteristics) and/or family history suggestive of fragile $\mathrm{X}$ syndrome are present. Further, with the advent of next-generation sequencing into clinical laboratories, numerous studies from academic and commercial laboratories have begun to establish the diagnostic utility of exome sequencing, with yields ranging from 10 to $41 \%^{10-13}$ in ID, DD, and ASD cohorts. Based on the higher diagnostic yields of CMA and exome sequencing in these cohorts, as well as the results of Weinstein et al. ${ }^{1}$ and others, we propose that these genome-wide tests become the recommended first-tier tests.

\section{DISCLOSURE}

The authors declare no conflict of interest.

Sureni V. Mullegama, $P h D^{1}$, Steven D. Klein, $P h D^{2}$, Dzung C. Nguyen, BS ${ }^{2}$, Arang Kim, $M S^{3}$, Rebecca Signer, $M S^{3}$, Michelle Fox, $M S^{3}$, Naghmeh Dorrani, $M S^{3}$, Andrea Hendershot, $M S^{4}$, Rebecca Mardach, $M D^{5}$, Robert Suddath, $\mathrm{MD}^{6}$, Katrina Dipple, $\mathrm{MD}, \mathrm{PhD}^{7}$, Eric Vilain, $M D, P h D^{2,3}$, Derek A. Wong, $M D^{3}$, Joshua L. Deignan, $\mathrm{PhD}^{1}$, Stephen D. Cederbaum, $M D^{2,3,6}$, Wayne W. Grody, MD, $P h D^{1,2,3}$ and

Julian A. Martinez-Agosto, $\mathrm{MD}, \mathrm{PhD}^{2,3,6}$

${ }^{1}$ Department of Pathology and Laboratory Medicine, David Geffen School of Medicine, University of California-Los Angeles, Los Angeles, California, USA; ${ }^{2}$ Department of 
Human Genetics, David Geffen School of Medicine, University of California-Los Angeles, Los Angeles, California, USA; ${ }^{3}$ Department of Pediatrics, David Geffen School of Medicine, University of California-Los Angeles, Los Angeles, California, USA; ${ }^{4}$ California Cryobank, Los Angeles, California, USA; ${ }^{5}$ Department of Pediatrics and MIND Institute, University of California-Davis, Davis, California USA; ${ }^{6}$ Department of Child and Adolescent Psychiatry, Resnick Neuropsychiatric Hospital, University of California-Los Angeles, Los Angeles, California, USA; ${ }^{7}$ Seattle Children's Hospital and Division of Genetic Medicine, Department of Pediatrics, University of Washington, Seattle, Washington, USA. Correspondence: Julian A. Martinez-Agosto (julianmartinez@mednet.ucla.edu)

\section{REFERENCES}

1. Weinstein V, Tanpaiboon P, Chapman KA, Ah Mew N, Hofherr, S. Do the data really support ordering fragile $X$ testing as a first-tier test without clinical features? Genet Med. E-pub ahead of print 25 May 2017.

2. Sherman S, Pletcher BA, Driscoll DA. Fragile X syndrome: diagnostic and carrier testing. Genet Med. 2005;7:584-587.

3. Moeschler JB; on behalf of the Committee on Genetics. Comprehensive evaluation of the child with intellectual disability or global developmental delays. Pediatrics. 2014;134:e903-e918.

4. Schaefer GB; on behalf of the Professional Practice and Guidelines Committee. Clinical genetics evaluation in identifying the etiology of autism spectrum disorders. Genet Med. 2008;10:301-305.

5. Schaefer GB; on behalf of the Professional Practice and Guidelines Committee. Clinical genetics evaluation in identifying the etiology of autism spectrum disorders: 2013 guideline revisions. Genet Med. 2013;15:399-407.
6. Shen $Y$, Dies KA, Holm IA, et al. Clinical genetic testing for patients with autism spectrum disorders. Pediatrics. 2010;125:e727-e735.

7. Macayran JF, Cederbaum SD, Fox MA. Diagnostic yield of chromosome analysis in patients with developmental delay or mental retardation who are otherwise nondysmorphic. Am J Med Genet A. 2006;140: 2320-2323.

8. Miller DT, Adam MP, Aradhya S, et al. Consensus statement: chromosomal microarray is a first-tier clinical diagnostic test for individuals with developmental disabilities or congenital anomalies. Am J Hum Genet. 2010;86:749-764.

9. Christofolini DM, Lipay MV, Ramos MA, et al. Screening for fragile $X$ syndrome among Brazilian mentally retarded male patients using PCR from buccal cell DNA. Genet Mol Res. 2006;5:448-453.

10. Lee $H$, Deignan JL, Dorrani N, et al. Clinical exome sequencing for genetic identification of rare Mendelian disorders. JAMA. 2014;312:1880-1887.

11. Soden SE, Saunders CJ, Willig LK, et al. Effectiveness of exome and genome sequencing guided by acuity of illness for diagnosis of neurodevelopmental disorders. Sci Transl Med. 2014;6:265ra168.

12. Yang $Y$, Muzny DM, Xia $F$, et al. Molecular findings among patients referred for clinical whole-exome sequencing. JAMA. 2014;312:1870-1879.

13. Yang, $Y$, Muzny DM, Reid JG, et al. Clinical whole-exome sequencing for the diagnosis of mendelian disorders. N Engl J Med. 2013;369: 1502-1511.

Advance online publication 21 September 2017. doi:10.1038/gim.2017.146 